\title{
All-ceramic cantilever resin-bonded fixed dental prostheses: a therapeutic option to replace a missing front tooth
}

\author{
M. Drossart ${ }^{1}$, R. Cheron ${ }^{2}$, G. Tirlet ${ }^{3}$ \\ 1 Doctor of Dental Surgery (Paris Descartes), Consultant with attached in consultation with \\ biomimetic (Charles Foix, Ivry), Private practice, Paris \\ 2 Doctor of Dental Surgery (Paris Descartes), former assistant lecturer Hospital University \\ of biomaterials and prosthesis, attached in consultation with biomimetic (Charles Foix, Ivry), \\ Private practice, Paris \\ ${ }^{3}$ Doctor in Dental Surgery (Paris Descartes), MCU-Paris Descartes PH-Charles Foix, Ivry-sur-Seine, \\ Member of the International Group of Bioemulation, Responsible for Biomimetic Consultation \\ (Charles Foix, Ivry-sur-Seine), Practice private, Paris
}

Thanks to Asselin Bonichon and Hélène and Didier Crescenzo for the quality of their prosthetic applications.

Case 1: Roman Cheron/Asselin Bonichon (New Technologies Laboratory)

Case 2: Maxime Drossart/Hélène and Didier Crescenzo (Oral Esthetic Laboratories)

Case 3: Gil Tirlet/Hélène and Didier Crescenzo (Oral Esthetic Laboratories)

\section{ABSTRACT}

The replacement of an anterior tooth remains a difficult challenge to overcome despite the many therapeutic solutions available. Given the diversity of clinical situations, the standardization of one protocol cannot be a satisfactory solution. This article aims to describe a therapeutic option to replace missing teeth in the anterior area. Cantilever bonded bridges today represent a real alternative to implants or orthodontic strategies for closing spaces. Validated more and more by the scientific literature, they allow good esthetic integration while offering possibilities of retreatment with very limited tissue damage.

\section{KEYWORDS}

single edentulous space, cantilever bonded bridge, ceramic, bonding

Address for correspondence:

Maxime Drossart

37, rue des Acacias - 75017

E-mail: Paris maxdrossart@gmail.com

Article received: $30 / 01 / 2017$. Accepted for publication: 26/02/2017.

This is an Open Access article distributed under the terms of the Creative Commons Attribution License (http://creativecommons.org/licenses/by/4.0), which permits unrestricted use, distribution, and reproduction in any medium, provided the original work is properly cited. 


\section{INTRODUCTION}

The bonded bridge is not a new treatment. Originally designed with perforated metal fins ${ }^{8,9}$, it then evolved into a two-fin design with no perforations resting on either side of the edentulous teeth. A classic pitfall of this type of restoration is the partial peeling of a fin. This failure caused some authors to cut off the peeled fin, creating a cantilever

\section{SCIENTIFIC VALIDITY}

Complex trauma, deep carious lesions, endodontic or periodontal failure, resorption, and agenesis are all causes that can lead to the replacement of an anterior tooth. The agenesis of a maxillary lateral incisor alone affects almost $2 \%$ of the population ${ }^{18}$. These treatments are complex, especially in young patients.

Dental practitioners need to know how to deal with a high smile line occasionally, continued growth of the maxilla, and a frequent lack of bone volume while anticipating future reinterventions. Although all these criteria should be considered for the long-term success, factoring all of them in makes the discussion regarding the treatment plan particularly difficult.

The implant-based solution should be considered but optimal esthetic integration may be difficult to achieve ${ }^{15,21}$ especially in patients with low bone volume $^{2}$ or continuous growth ${ }^{14,16,22,23,3}$. Moreover, the risk of the prosthetic components appearing through the marginal gingiva is still present despite progress in terms of the design of the transmucousal prosthesis ${ }^{10,17}$. design. Contrary to their expectations, they found that these "precarious" situations were sustainable. In this article, we will present the scientific validity of these types of restorations, now made in ceramic. We will detail their clinical benefits and the treatment sequence, which often has to be coupled with orthodontic treatments.

The ceramic cantilever bonded bridges seem to be an interesting alternative to address these problems. Indeed, they facilitate the management of the growth lof the alveolar bone which serves as a bone base). They also allow better management of the lack of bone volume and hide the transgingival floor from view. Finally, compared with implant therapy, this solution also decreases the duration of treatment drastically, especially if a bone graft is needed.

This is not a new solution. It has already been widely tested with metal frames ${ }^{20}$. Botelho published in 2014 a clinical evaluation on 211 bonded cantilever bridges ${ }^{4}$ and found success rates of $84 \%$ after 15 years.

More surprisingly, it is more efficient than two-wing bonded bridge solutions with higher success rates ${ }^{25}$. This information, which may seem counterintuitive (it is often thought to be better to stick with two fins), is clearly explained by the study of biomechanics. Indeed, the support on two teeth with different preferential mobilities generates strong stresses at the bonding joints, 
which often results in a partial detachment of only one of the two fins. The use of a cantilever makes it possible to use the periodontal ligament of the pillar tooth as a stress absorber because the cantilever and the tooth are now one. Therefore, the multiplication of the number of support fins contributes to a diminished prognosis rather than aiding our reconstruction?

The first to explore this route was Mathias Kern ${ }^{11,12,13}$ and today reports a $95.4 \%$ success after 15 years with cantilever bridges made from InCeram Alumina. These encouraging results

\section{CLINICAL SEQUENCE}

- Photos (intraoral, smiling, smiling face, and face with spreader).

- Esthetic analysis, ${ }^{5,6}$ : this makes it possible to anticipate, by measures of spaces and by the positioning of virtual teeth on the intraoral photographs, the therapeutics to put in place to optimize the esthetic integration of future restorations. Thus, this analysis can help to make an early indication of orthodontic or periodontal treatment and will therefore be very useful in establishing a treatment plan.

Similarly, at the end of orthodontic treatment, it is the only reliable way to update the criteria for proper positioning of the teeth before removing the false tooth .

- Generally, the orthodontist sticks a dummy tooth to a bracket to integrate it into the arch and not to leave an edentulous space. It will therefore provide a thermoformed gutter incorporating the (false) tooth/teeth that have led some authors to test other materials including Ries et al. who in 2006 tried using E-max ${ }^{19}$. The adhesion capabilities of this ceramic, the excellent optical properties, and the simplicity of implementation in the laboratory make it the ideal choice for this kind of therapy. This is especially true when it is necessary to combine the replacement of a tooth with a cantilever bridge with other therapies that use all-ceramic processes (facets, crowns). The use of a single material for all restorations makes achieving an esthetic result simpler and more predictable ${ }^{24}$.

will be used immediately after detachment to ensure esthetic continuity but also to maintain the position of the teeth.

- An impression can then be made to create the esthetic wax model.

- Transfer of the esthetic model directly to the mouth using a Bis-Acryl resin. This step, very simple and fast, is essential to validate the esthetic integration of the model with the dynamics of the lip and the face. It also allows us to validate the position of the intermediate bridge (which will be used in the preparation of the edentulous site), as well as the shape of the teeth eventually restored by facets or crowns.

- The preparations can be made once the model has been validated. The aim is to prepare the palatal surface of the cantilever bridge support tooth, as well as to create a "cradle" in the lining of the edentulous site, which is ideal for the attachment of bridge 


\section{Clinical Case \# 1}

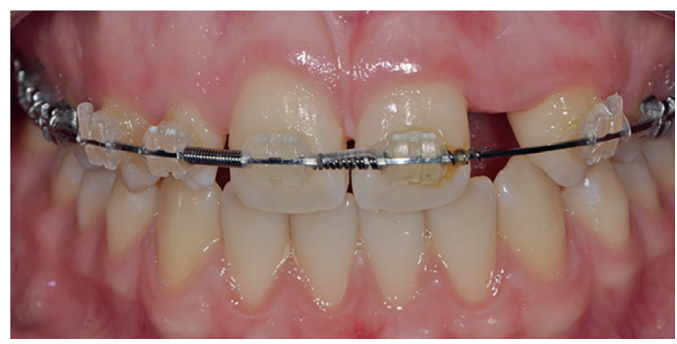

Figure 1

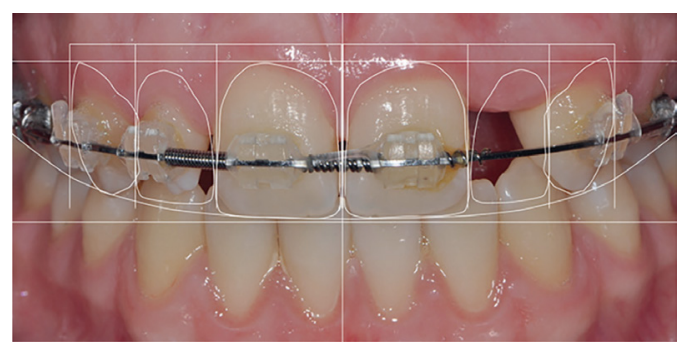

Figure 3

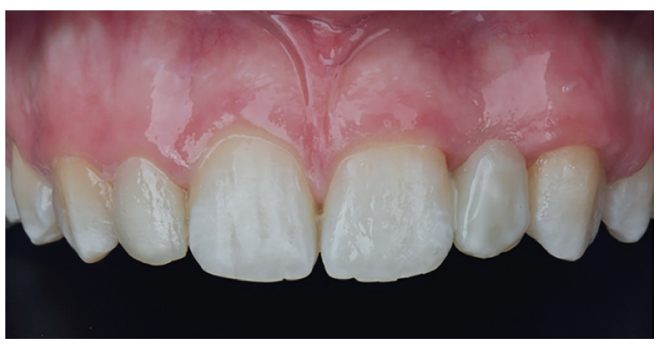

Figure 5

Figure 1: Initial Situation during the first consultation. The patient was referred by her orthodontist (Dr. Montluc) to validate the positions before attaching the brackets.

Figure 2: The very first step in esthetic analysis is to replace the teeth in the facial context by orienting the intraoral views relative to the bi-pupillary axis.

Figure 3: This allows us to validate the correct coherence between the dental axes and the vertical axis of the face, as well as to confront the dental positions to an "ideal" model of ratios and positions. Here, the situation is quite favorable, subject to the (obvious) replacement of 22 and a form correction of 12 .

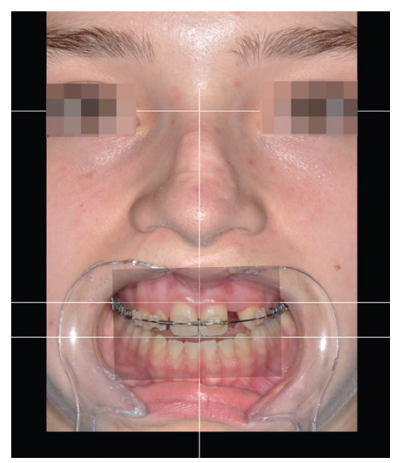

Figure 2

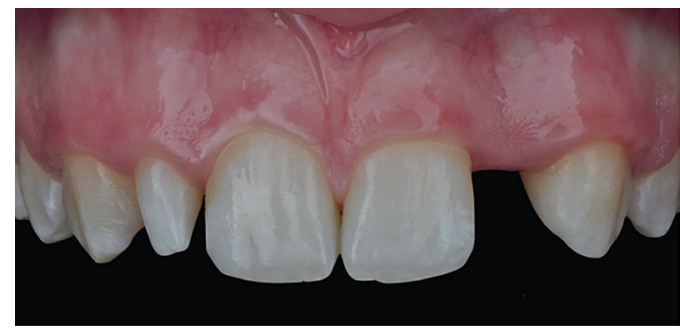

Figure 4

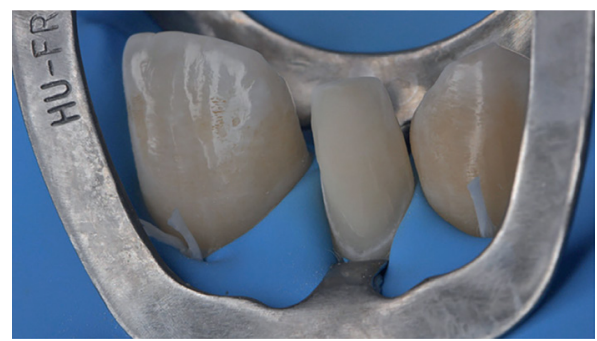

Figure 6

This analysis also suggests the relevance of a minor gingivoplasty to slightly increase the heights of the crowns.

Figure 4: After attaching the brackets, an impression is immediately taken to make a wax model carried out by the prosthetist.

Figure 5: The model is transferred directly to the mouth for better communication with the patient. Here, the color of 22 was too gray, a fluid-white composite was quickly placed and cured lightly for the esthetic integration of the model.

Figure 6: A preparation for film facet was performed on 12 in the thickest part of the enamel. 
Clinical case No. 1 (cont'd)

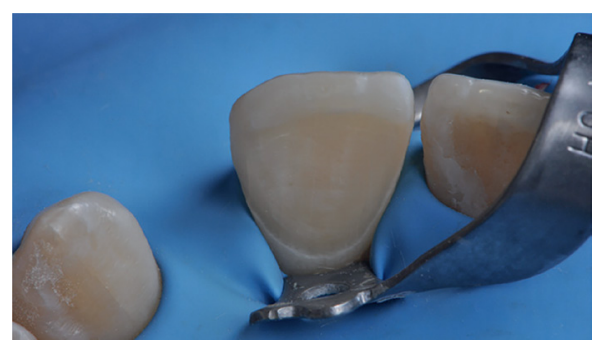

Figure 7

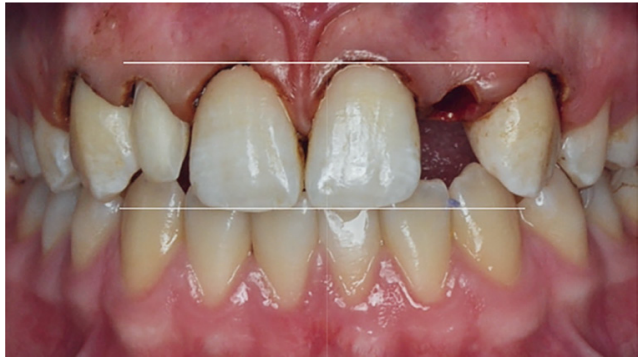

Figure 9

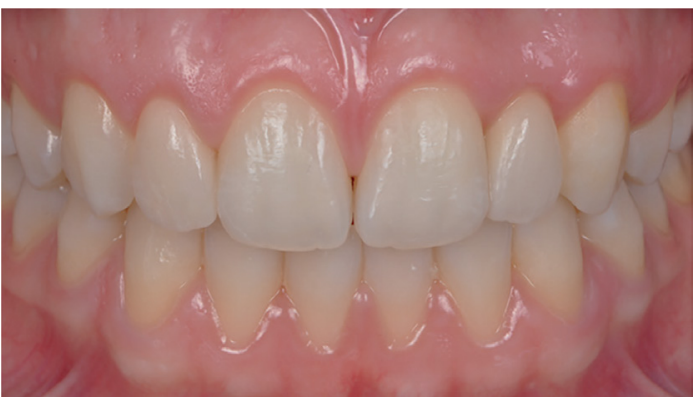

Figure 11

Figure 7: The same principle of minima preparation is applied to the palatal preparation for the cantilever bridge based on 21 and replacing 22. Figure 8: The edentulous site is "sculpted" to accommodate the intermediary of the bridge. This step can be implemented using an irrigated diamond drill or a laser.

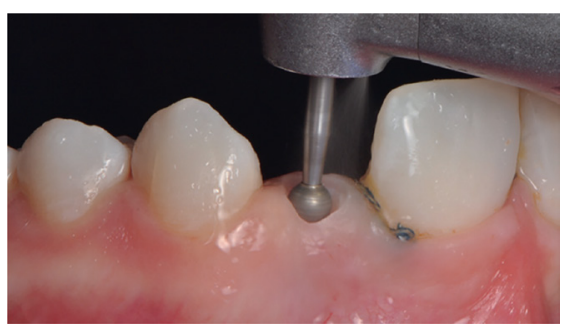

Figure 8

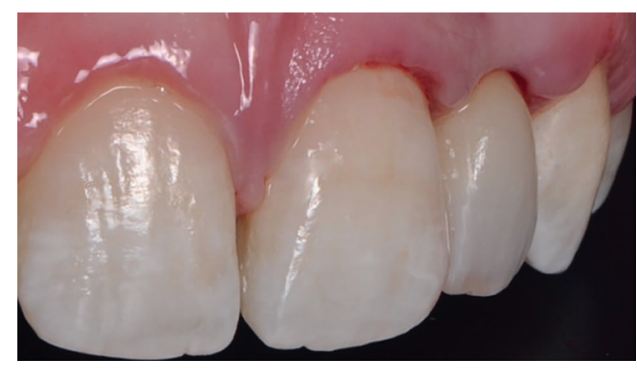

Figure 10

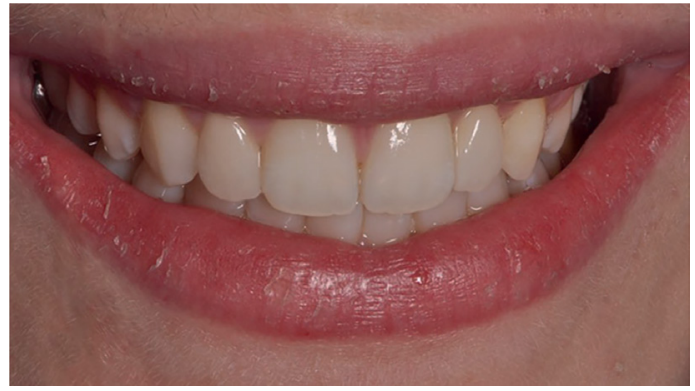

Figure 12

Figure 9: The coronal elongation here could be done by simple gingivoplasty with an electric scalpel, respecting the biological space.

Figure 10: Right after attachment.

Figure 11:3-month view.

Figure 12: View of the smile. 
Clinical case No. 2

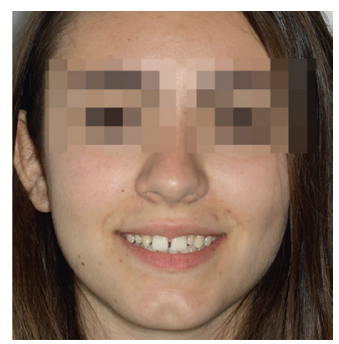

Figure 1

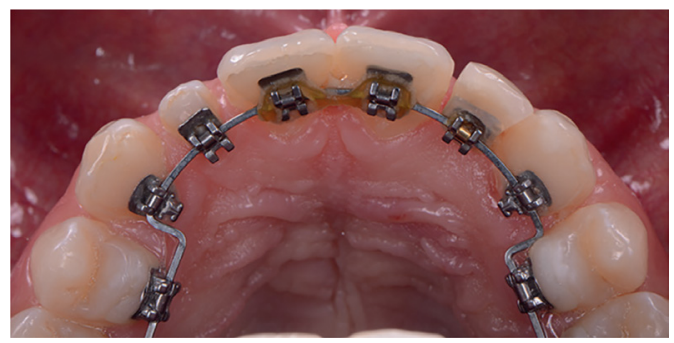

Figure 3

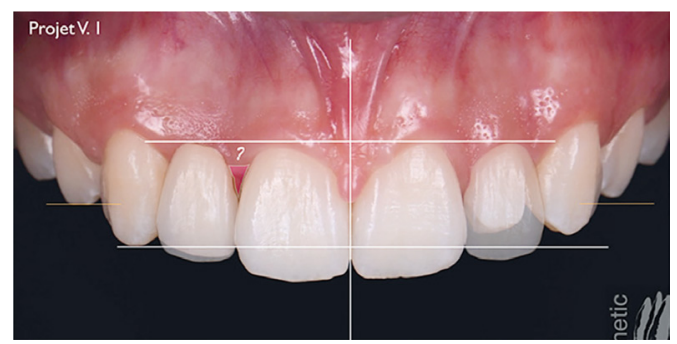

Figure 5

Figure 1: Initial Situation. The patient wishes to improve her smile.

Figure 2: The patient has an agenesis of 12 and a microdontia of 22. 13 has evolved in place of 12, and 53 is stuck on the arch. She is referred to the orthodontist to establish a multidisciplinary plan of treatment.

Figure 3: Current view of the definition of orthodontic treatment (David Issembert, Paris). The interincisal diastema is closed. 13 is in place of 53, which has been extracted and the space of 12 is now open.

Figure 4: The lingual device is used to under-

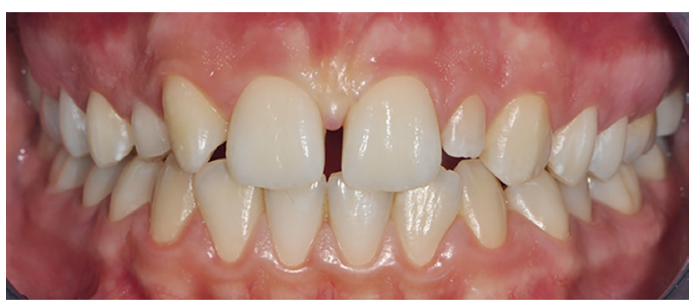

Figure 2

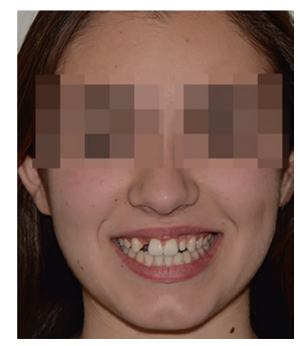

Figure 4

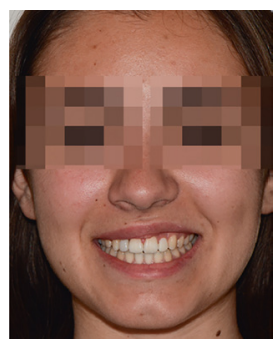

Figure 6

stand the patient's smile and perform the esthetic analysis before detachment. The mold on 12 is removed at the time of the photos and put back in place after the session.

Figure 5: Virtual esthetic analysis allows us to validate the symmetry of the spaces for 12 and 22. The Virtual Esthetic Project (HD Crescenzo) model focuses on the mesial papilla of 12, and the need for a more apical 1-mm limit for restoration over 22.

Figure 6: A mock-up can be made to validate the model with the patient 
Clinical case No. 2 (cont'd)

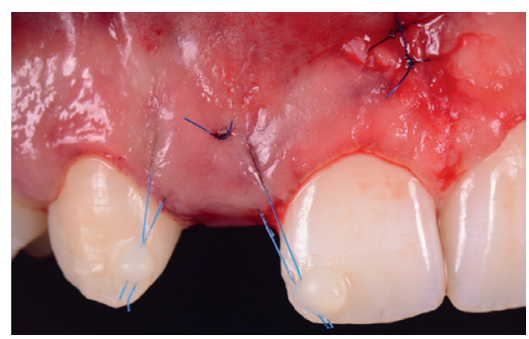

Figure 7

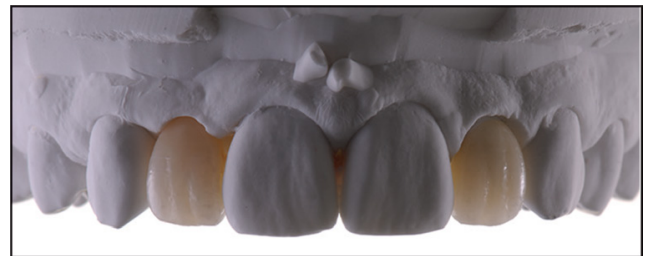

Figure 9

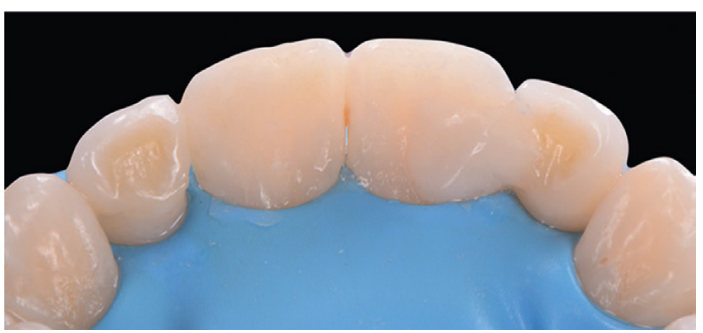

Figure 11

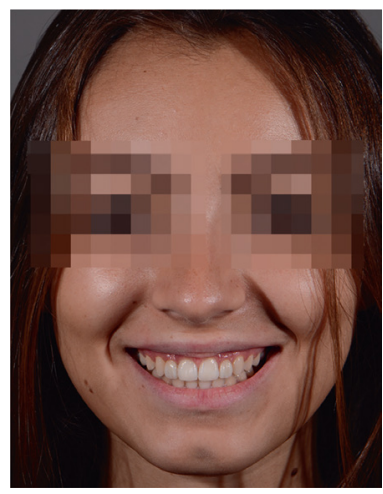

Figure 13

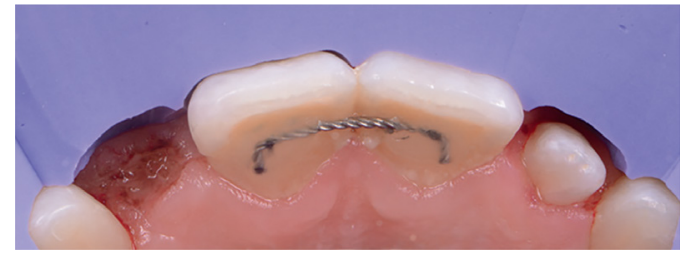

Figure 8

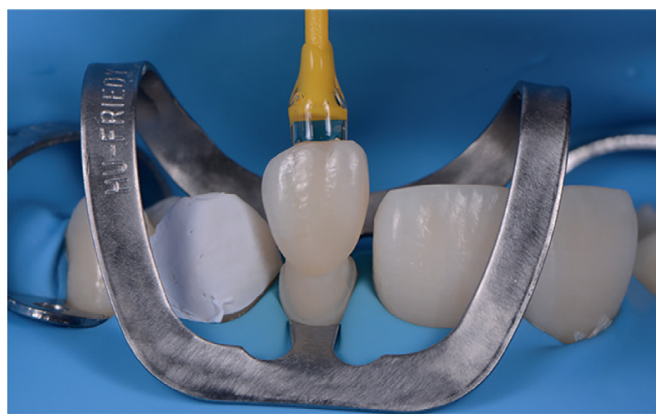

Figure 10

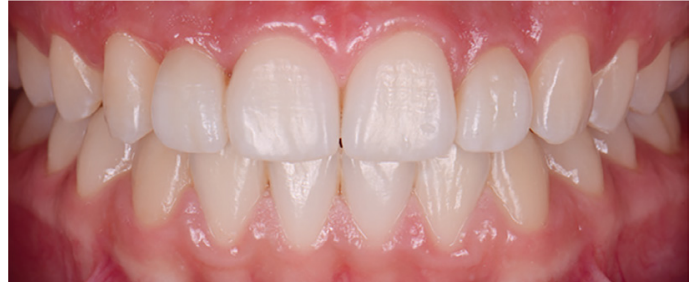

Figure 12

Figure 7: A connector buried in tunnel (Leon Pariente, Paris) is made to promote the integration of the cantilever bridge by thickening the tissues at the intermediate level.

Figure 8: The silicone cast from the mock-up validates the correct position of 22. Its slight lingual position allows a minimal preparation while leaving room for the ceramics. Even if the patient wears a contention gutter that contains 12, the orthodontist (David Issembert, Paris) took care to make a temporary restraint (withdrawn before the preparation of the palate of 11) to prevent the re-opening of the diastema 1121.

Figure 9: The use of E-max (Ivoclar Vivadent), a reinforced ceramic glass, makes it possible to make the cantilever bridge and facet in the same material. (Oral Esthetic Laboratory, Hélène and Didier Crescenzo, Cogolin). 
Figure 10: Attachment of 22.

Figure 11: Palatal view after attachment of 12 and 22.

\section{Clinical Case \# 3}

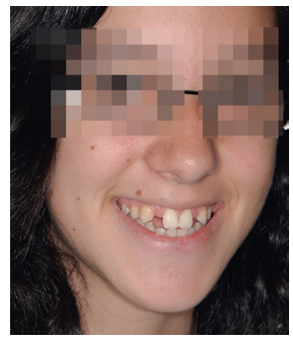

Figure 1

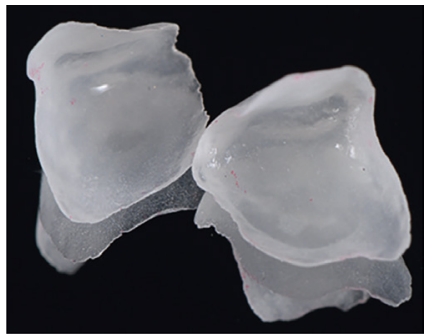

Figure 3

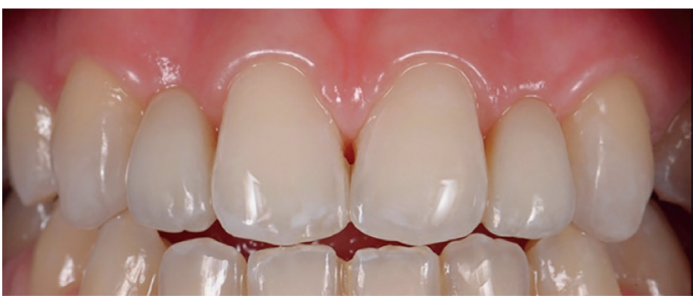

Figure 5

Figure 1: Initial Situation. This young 14-yearold patient has a bilateral agenesis. Orthodontic treatment was conducted over 2 years (Dr. Anne Beaugrand).

Figure 2: Initial Situation. Agenesis of 12 and 22 (Orthodontics Dr. Anne Beaugrand).

Figure 3: Ceramic implants (E. max Ceram) makes it possible to optically straighten the axis of the two canines and to close the vestibular joints.
Figure 12: Final intraoral view.

Figure 13: Final view of the face.w

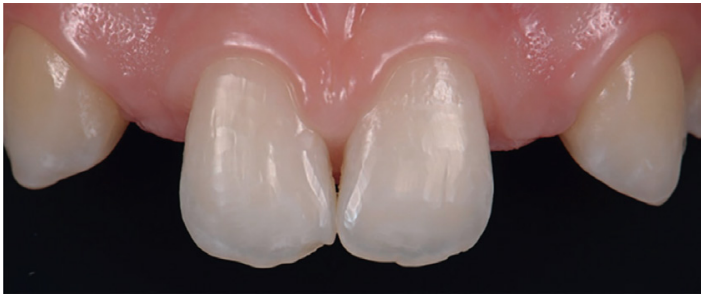

Figure 2

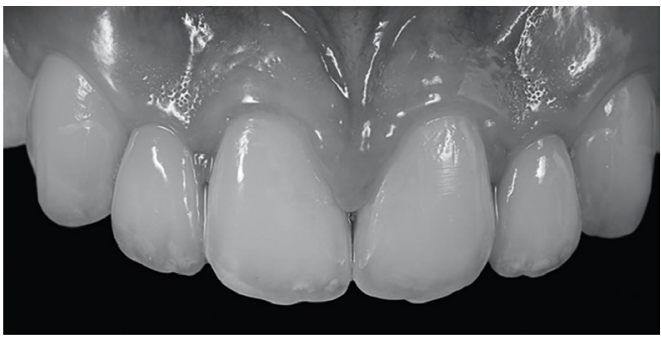

Figure 4

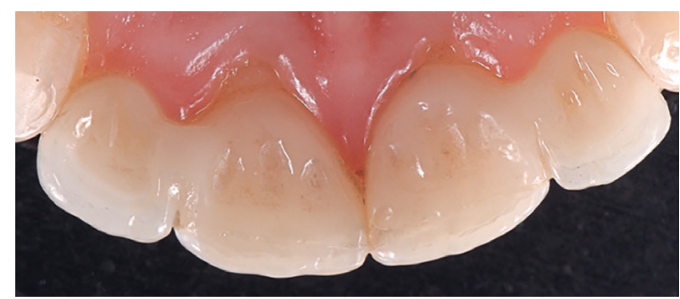

Figure 6

Figure 4: Situation after attaching two cantilever bridges with E. Max replacing 12 and 22 and ceramic implants on 1 and 23 (Produced by Oral Esthetic Laboratories).

Figure 5: Clinical view in black and white that allows us to assess the optical properties of lithium disilicate in terms of brightness. Figure 6: Final clinical palatal view after 2 years. 
Clinical case No. 3 (cont'd)

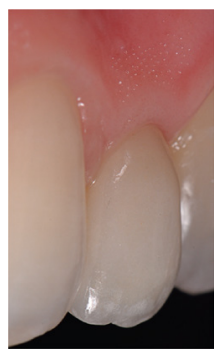

Figure 7

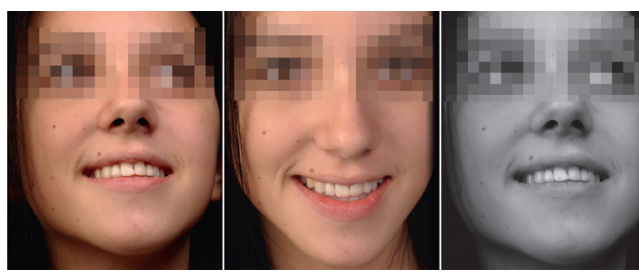

Figure 9

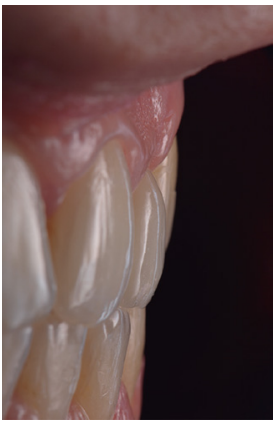

Figure 11

Figure 7: Integration of cantilever bridge.

Figure 8: Final clinical view after 3 years (Photo with lateral light box). The use of lithium disilicate reinforced ceramics has the enormous advantage of avoiding any opacity effect on the teeth bearing the fins, which remains one of the main disadvantages of metal alloys.

Figure 9: Final dynamic views of face.

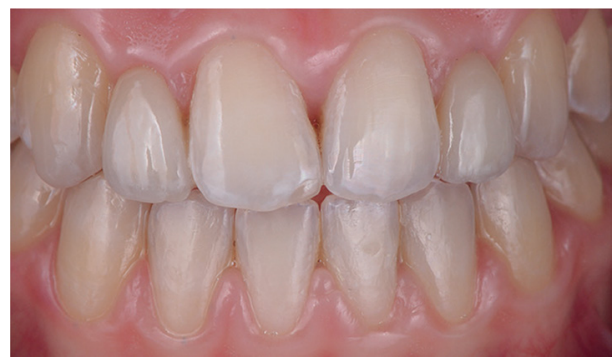

Figure 8

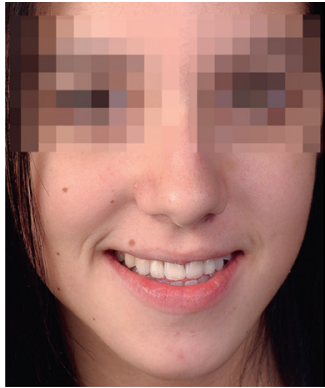

Figure 10

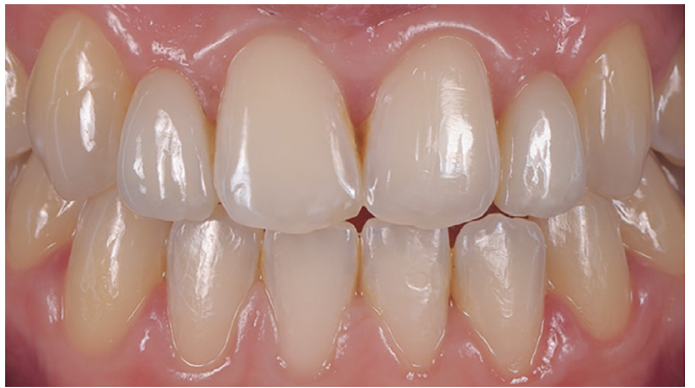

Figure 12

Figure 10: View of the symmetrical integration of the teeth in the face.

Figure 11: Emergence profile of 22 and biological integration. Clinical follow-up after 5.5 years.

Figure 12: Integration of cantilever bridges with a clinical follow-up after 5.5 years. 
mediators. This is referred to as the "ovalization" of the edentulous ridge.

- It is the validation of the mock-up which allows us to locate this cradle correctly.

Similarly, the mock-up allows a controlled preparation of the teeth so that a facet may be attached.

- The impression is made immediately after the preparation.

- Preparations almost exclusively affecting enamel, a little or no watertight delay will not be detrimental.
The objective here is essentially esthetic. A new "mock-up" can be done again (on prepared teeth). It can be left in this state or stabilized by a thermoformed gutter (made on a plaster duplicate of the wax model).

- Fitting.

- Attachment.

This analysis also suggests the relevance of a minor gingivoplasty to slightly increase the heights of the crowns.

\section{CONCLUSION}

The technique of ceramic cantilever-bonded bridges is now a plausible alternative to implant therapies. Considered as temporary treatments by many, they offer real benefits in the medium and long term; in addition to their lower cost, they allow better predictability of the esthetic result and are much more adaptable, especially when restructuring is needed for growth. Technically simple if we master the fundamentals of adhesive dentistry, this method how- ever requires a good treatment plan. The esthetic analysis on photos allows us to understand the positions and the dental ratios, as well as the gingival and osteomucosal contours. It is through this analysis that we can define the parameters to be adapted, by orthodontics or osteomucosal surgery, to conduct them under ideal conditions and to guarantee an optimal result.

Conflict of Interest: The authors declare that there is no conflict of interest.

\section{BIBLIOGRAPHY}

1. Attal JP, Tirlet G. Le cantilever : une nouvelle géo métrie pour les bridges collés Revue de la littérature. Réalités Clin 2015;26:25-34.

2. Belser UC, Bernard JP, Buser D. Implant-supported restorations in the anterior region: prosthetic considerations. Pract Periodontics Aesthet Dent 1996;8:875-83; quiz 884.

3. Bernard JP, Schatz JP, Christou P, Belser U, Kiliaridis S. Long-term vertical changes of the anterior maxillary teeth adjacent to single implants in young and mature adults: A retrospective study. J Clin Periodontol 2004;31:1024-1028.

4. Botelho MG, Ma X, Cheung GJ, Law RK, Tai MT, Lam WY. Long-term clinical evaluation of 211 two-unit cantilevered resin-bonded fixed partial dentures. J Dent 2014;42:778-784. 
5. Coachman C. et al. Smile design: From digital treatment planning to clinical reality. Quintessence, 2012.

6. Crescenzo H, Crescenzo D. Le Projet virtuel esthétique - Un nouvel outil pour les traitements esthétiques. Strat prothétique 2015;15.

7. Dunne S.M, Millar BJ. A longitudinal study of the clinical performance of resin-bonded bridges and splints. Br Dent J 1993;17:405-11.

8. Eshleman JR, Douglas HB, Barnes D. The acid etch bonded porcelain fused to metal bridge. Va Dent J 1979;56:16-9.

9. Howe DF, Denehy GE. Anterior fixed partial dentures utilizing the acid-etch technique and a cast metal framework. J Prosthet Dent 1977;37:28-31.

10. Ishikawa-Nagai S, Da Silva JD, Weber HP, Park SE. Optical phenomenon of peri-implant soft tissue. Part II. Preferred implant neck color to improve soft tissue esthetics. Clin Oral Implants Res 2007;18:575-80.

11. Kern M, Glaser R. Cantilevered All-Ceramic, Resin-Bonded Fixed Partial Dentures: A New Treatment Modality. J Esthet Dent 1997;9.

12. Kern M. Clinical long-term survival of two-retainer and fixed partial dentures. Quintessence Int (Berl) 2005;36:141-8.

13. Kern M. Fifteen-year survival of anterior all-ceramic cantilever resin-bonded fixed dental prostheses. J Dent 2017;56:133-5.

14. Lautrou A. [Growth and morphogenesis of the cra niofacial bones. Applications in orthodontics. The concepts of J Delaire]. Orthod Fr 2002;73:5-18.

15. Moberg LE, Köndell PA, Kullman L, Heimdahl A, Gynther GW. Evaluation of single-tooth restorations on ITI dental implants. A prospective study of 29 patients. Clin Oral Implants Res 1999;45-53.

16. Oesterle LJ, Cronin RJ. Adult growth, aging, and the single-tooth implant. Int J Oral Maxillofac Implants 2000:15:252-60.

17. Park SE, Da Silva JD, Weber HP, Ishikawa-Nagai S. Optical phenomenon of peri-implant soft tissue. Part I. Spectrophotometric assessment of natural tooth gin giva and peri-implant mucosa. Clin Oral Implants Res 2007;18:569-574.

18. Polder BJ, Van't Hof MA, Van der Linden FP, Kuijpers-Jagtman AM. A meta-analysis of the prevalence of dental agenesis of permanent teeth. Community Dent Oral Epidemiol 2004;32:217-26.

19. Ries S, Wolz J, Richter EJ. Effect of design of all-ceramic resin-bonded fixed partial dentures on clinical survival rate. Int J Periodontics Restorative Dent 2006;26:143-9.

20. Samama Y. Fixed bonded prosthodontics: a 10-year

21. follow-up report. Part I: Analytical overview. Int J Periodontics Restorative Dent 1995;15:424-35.

22. Searson L, Meredith N. The role of implants in restorative dentistry: prosthesis design and esthetic considerations. Dent Update 1997;24;388-90.

23. Thilander B, Odman J, Gröndahl K, Lekholm U. Aspects on osseointegrated implants inserted in growing jaws. A biometric and radiographic study in the young pig. Eur $\mathrm{J}$ Orthod 1992;14:99-109.

24. 2Thilander B, Odman J, Lekholm U. Orthodontic aspects of the use of oral implants in adolescents: a 10-year follow-up study. Eur J Orthod 2001;23:715-731. 
24. Tirlet $G$, Attal JP. Les bridges collés cantilever en vitro céramique renforcée au disilicate de lithium Raisons du choix et mise en œuvre clinique. Réalités Clin 2015;26;35-46.

25. van Dalen A, Feilzer AJ, Kleverlaan CJ. A literature review of two-unit cantilevered FPDs. Int J Prosthodont 2004;17:281-4. 